\title{
LETRAMENTO JURÍDICO, LEGISLAÇÃO, DIREITO E EDUCAÇÃO
}

\author{
LEGAL LITERACY, LEGISLATION, LAW, AND EDUCATION
}

\author{
DANTE BATISTA SILVA ${ }^{1}$ \\ Universidade São Francisco - USF \\ Bolsista Institucional \\ batista.dante@gmail.com
}

RESUMO - O artigo tem como objeto de análise a reflexão e o letramento jurídico na educação superior a partir da leitura do $A$ Nova Carta de $A B C$, de Olavo Bilac (2015)². O objetivo é analisar, nesse conto, como se configura uma investigação histórica. Narra-se nele a história de um menino de seis anos que se alfabetizou tendo como material de instrução para seu letramento as frases que viu e decorou assistindo filmes, o que lhe possibilitou ir aprendendo palavras referentes a um período importante da cultura europeia: a Belle Époque ${ }^{3}$. A pesquisa se justifica pela necessidade de se discutir sobre o aprendizado que as pessoas vão adquirindo, o qual não tem 'fórmula pronta' e tampouco é linear. Por isso, centramo-nos no que esse menino viu nas tirinhas dos filmes de cinema nos anos de 1908 a 1911, e também na memória pessoal do autor deste trabalho ao estudar a língua e a cultura japonesas, numa aproximação e convergência de olhares com o letramento jurídico, o direito e a educação.

Palavras-chave: direito, educação, letramento, Olavo Bilac, sensibilidades

ABSTRACT - This article has as its object of analysis and reflection the legal literacy in higher education from the reading of The New ABC Letter ( $A$ Nova Carta de ABC), by Olavo Bilac (2015). The objective is to analyze, in this tale, how a historical investigation is configured. This tale tells the story of a six-year-old boy who literated himself, using as instructional material for his literacy, the phrases he heard and memorized watching the movies, which allowed him to learn words referring to an important period of European culture: The Belle Époque. The research is justified by

\footnotetext{
${ }^{1}$ Bacharel em Direito (UNIBAN), Especialista em Direito Empresarial (UNIMEP), Mestrando pelo PPGSSE/USF - Programa de Pós-Graduação Stricto Sensu em Educação da Universidade São Francisco/USF - campus Itatiba - SP. Membro do Grupo de Pesquisa TCTCLAE - Teoria Crítica e Teorias Críticas Latino-Americanas e Educação.

${ }^{2}$ Esse conto de Olavo Bilac foi publicado em uma coletânea intitulada Tempos de escola: contos, crônicas e memórias. São Paulo: Boa Companhia, 2015.

${ }^{3}$ A expressão Belle Époque ou Bela Época, ficou assim conhecida por expressar a cultura cosmopolita da Europa, quando da passagem do século XIX para o século XX. Essa fase foi marcante porque iniciou-se avanços significativos com o progresso industrial, tecnológico, cientifico e cultural, especialmente na Europa, tendo repercussão também no Brasil.
} 
the need to discuss about the learning that people are acquiring, which has no 'ready formula' and is not linear either. Therefore, we focus on what this boy saw in the strips of cinema films from 1908 to 1911, and also on the personal memory of the author of this tale when he was studying the Japanese language and culture, in an approach and convergence of glances with the legal literacy, law and education.

Key Words: law, education, literacy, Olavo Bilac, sensitivities

\section{INTRODUÇÃO}

A escolha do conto supracitado nos aproximou do letramento jurídico de modo geral, dada a possibilidade de uma análise no contexto da educação superior no Brasil.

Compreendemos que o processo educativo não segue uma fórmula pronta; que a educação não é um adestramento, uma adaptação; que o letramento jurídico foi escrito para a sociedade e não apenas para um grupo especifico; que a falta de sensibilidade ou ausência de uma educação de qualidade não permite a formação de um sujeito crítico, cujo fator alienante é determinante para reforçar o desinteresse também no ensino superior e distanciar os aprendizes do letramento jurídico.

Os autores teóricos que embasam esta análise são: André Chervel (1990), historiador francês, estudioso da cultura e do ensino de língua; o sociólogo francês Le Breton (1953), que contribui para a compreensão de uma educação das sensibilidades; o educador Marcus Aurélio Taborda de Oliveira et al. (2014) que permite uma visão histórica do processo de formação das sociedades e da educação.

\section{VIDA E OBRA DE OLAVO BILAC E O CONTO $A$ NOVA CARTA DE ABC}

Inicia-se o artigo com uma citação da Academia Brasileira de Letras, sobre a vida e obra do escritor-poeta e jornalista, Olavo Bilac ${ }^{4}$ :

\footnotetext{
Olavo Braz Martins dos Guimarães Bilac, jornalista, poeta, inspetor de ensino, nasceu no Rio de Janeiro, RJ, em 16 de dezembro de 1865, e faleceu, na mesma cidade, em 28 de dezembro de 1918. Um dos fundadores da Academia Brasileira de Letras criou a cadeira $\mathrm{n}^{\circ}$. 15, que tem como patrono Gonçalves Dias. Eram seus pais o Dr. Braz Martins dos Guimarães Bilac e D. Delfina Belmira dos Guimarães Bilac. Após os estudos primários e secundários, matriculou-se na Faculdade de Medicina no Rio de Janeiro, mas desistiu no $4^{\circ}$. ano. Tentou, a seguir, o curso de Direito em São Paulo, mas não passou do primeiro ano. Dedicou-se desde cedo ao jornalismo e à literatura. Teve intensa participação na política e em campanhas cívicas, das quais a mais famosa foi em favor do
}

\footnotetext{
${ }^{4}$ Fonte: $\underline{\text { bttp:// wmw.academia.org.br/academicos/olavo-bilac/biografia }}$
} 
serviço militar obrigatório. Fundou vários jornais, de vida mais ou menos efêmera, como A Cigarra, O Meio, A Rua. Na seção "A Semana" da Gazeta de Notícias, substituiu Machado de Assis, trabalhando ali durante anos. É o autor da letra do Hino à Bandeira.

A partir da leitura desse conto, que foi publicado no Jornal Gazeta de Notícias, do Rio de Janeiro, e também noticiado pelo Jornal Correio Paulistano ${ }^{5}$ em 19/01/1908., constata-se que o menino do conto aprende a ler sozinho, sem instrução e sem nenhum tipo de acompanhamento pedagógico, podendo-se considerar que se alfabetizou a partir do material que dispunha, dos programas cinematográficos, de sua curiosidade e perspicácia, o que o faz querer decifrar a língua escrita nas frases, então, passa a memorizar as frases e com elas inicia-se seu processo de alfabetização e letramento.

Ao analisar o conto, foi possível ao pesquisador deste texto lembrar-se de sua experiência de alfabetização no letramento de uma outra língua estrangeira, a língua japonesa, na qual se estudam três alfabetos distintos: o primeiro é o Hiragana, uma letra que corresponde ao som de duas letras juntas no português, estuda-se esse primeiro alfabeto japonês no início do ensino da língua, o segundo alfabeto é chamado de Katakana e é utilizado para expressar as palavras de outras línguas, assim como a escrita de nomes estrangeiros, e o terceiro alfabeto que particularmente é considerado o mais difícil, é o Kanji , no qual cada símbolo representa uma frase completa, obrigando o leitor a decorar a imagem de acordo com sua significação. Seguem fotos que ilustram os alfabetos, as fontes de letramento da língua japonesa:

\begin{tabular}{|c|c|c|c|c|}
\hline \multicolumn{5}{|c|}{ Hiragana } \\
\hline あ & $v_{i}$ & 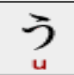 & $\underset{\mathrm{e}}{\lambda}$ & 打 \\
\hline$\underset{k a}{\text { Da }}$ & $\underbrace{}_{\mathrm{ki}}$ & $\sum_{\mathrm{ku}}$ & けチ & $\underbrace{2}_{\mathrm{ko}}$ \\
\hline$\underset{\text { sa }}{d}$ & $\mathrm{~L}_{\text {shi }}$ & $\mathrm{d}_{\text {su }}$ & せ & そ \\
\hline た & $\underset{c h i}{\zeta}$ & $\overrightarrow{t s u}_{\text {ssu }}$ & $\tau_{t e}$ & $\sum_{\text {to }}$ \\
\hline な & $l_{\mathrm{ni}}$ & $\underset{\text { nu }}{\not 2}$ & $\downarrow_{\text {ne }}$ & $D_{\text {no }}$ \\
\hline $\begin{array}{l}\text { は } \\
\end{array}$ & ひi & $\underset{\mathrm{fu}}{\zeta_{\mathrm{u}}}$ & $\widehat{\text { he }}$ & $\begin{array}{l}\text { ほ } \\
\text { ho }\end{array}$ \\
\hline ま & $\underset{\mathrm{mi}}{\text { み }}$ & $\underbrace{}_{m u}$ & $\underset{m e}{\phi}$ & 8 \\
\hline$\underset{\text { ya }}{\text { P }}$ & & $ゆ_{\text {yu }}$ & & $\underset{\text { yo }}{5}$ \\
\hline$\sum_{\text {ra }}^{5}$ & $\bigvee_{\mathrm{ri}}$ & 君 & 祀 & $3_{\mathrm{ro}}$ \\
\hline わ & & & & を \\
\hline$\underset{n}{2}$ & & & & \\
\hline
\end{tabular}

\begin{tabular}{|c|c|c|c|c|}
\hline & & & & \\
\hline$\underset{\mathrm{a}}{\mathcal{P}}$ & T & ウ & $\frac{I}{\mathrm{e}}$ & 才 \\
\hline$\underset{\mathrm{ka}}{\text { 力 }}$ & $\underset{\mathrm{ki}}{\text { キ }}$ & ${ }_{\mathrm{ku}}^{\text {ク }}$ & ケ & $\underset{\mathrm{ko}}{コ}$ \\
\hline$\underset{\mathrm{sa}}{\text { サ }}$ & $\underset{\text { shi }}{\text { N }}$ & $\underset{\text { su }}{\text { 又 }}$ & $\underset{\text { se }}{セ}$ & so \\
\hline 女 & $\underset{\text { chi }}{\text { f }}$ & 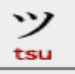 & 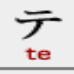 & $\begin{array}{l}\text { 下 } \\
\text { to }\end{array}$ \\
\hline$\underset{n a}{J}$ & $\frac{\overline{n i}}{{ }^{2}}$ & $\underset{\mathrm{nu}}{\text { 又 }}$ & $\underset{n e}{\text { 京 }}$ & $\gamma_{\text {no }}$ \\
\hline ha & $\underset{\mathrm{hi}}{ヒ}$ & ᄀ. & $\widehat{\text { he }}$ & $\underset{\text { ho }}{\text { 小 }}$ \\
\hline$\underset{\mathrm{ma}}{\mathrm{T}}$ & $\underset{\mathrm{mi}}{ミ}$ & $\underset{\mathrm{mu}}{\Delta}$ & $\underset{m e}{x}$ & $\underset{\mathrm{mo}}{\mathcal{E}}$ \\
\hline$\underset{\text { ya }}{\longrightarrow}$ & & $\frac{7}{\text { yu }}$ & & $\underset{\text { yo }}{\exists}$ \\
\hline$\overline{\text { ra }}$ & ${ }_{\mathrm{ri}}$ & $\underset{\mathrm{ru}}{\text { U }}$ & $\underset{\text { re }}{\nu}$ & $\underset{\text { ro }}{\square}$ \\
\hline 7 & & & & ᄀ \\
\hline$v_{n}$ & & & & \\
\hline
\end{tabular}

\footnotetext{
${ }^{5}$ Primeiro jornal diário de São Paulo e o terceiro do Brasil, o único jornal brasileiro que apoiou a Semana de Arte
} Moderna de São Paulo em 1922, encerrou suas atividades em 1963. 
Fonte: Aulas de Japonês 6

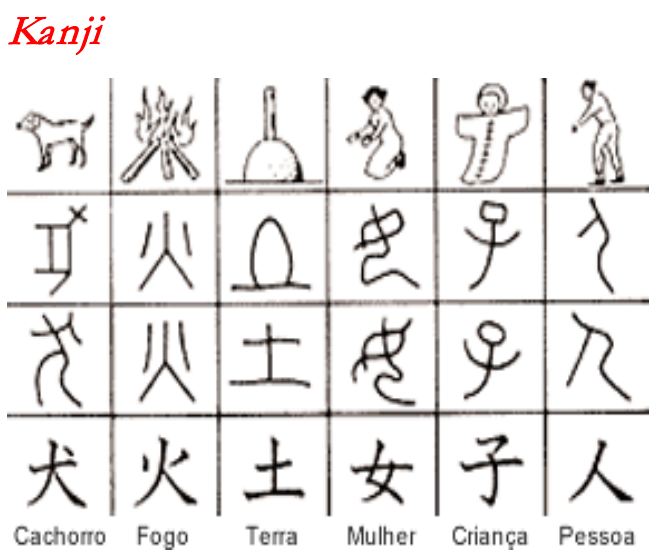

Fonte: Aulas de Japonês ${ }^{7}$

Voltando ao conto, o relato do menino de seis anos, de autoria de Olavo Bilac, faz repensar a educação, cujo processo não necessita seguir ao pé da letra um modelo único de aprendizado, como se segue uma fórmula pronta ou uma espécie de adestramento que torna o aprendizado mecanizado, e provavelmente sem sentido, sem um trabalho de sensibilização, nem preparo para uma formação crítica.

O aprendizado do menino, parece que vai ao encontro da experiência na aprendizagem da língua japonesa, em especial ao alfabeto Kanji, no qual os aprendizes aprendem a decorar os símbolos, justamente porque eles representam frases inteiras.

Ao estudar a história da educação, por uma série de questões, inclusive pela possibilidade de aprender sobre o letramento de documentos, fontes, monumentos, acervos históricos, pode-se destacar em especial, o aprendizado sobre o letramento jurídico para estudantes de diversas áreas do conhecimento, em cursos de graduação, o que certamente faz compreender a importância da construção curricular de uma disciplina jurídica para estudiosos que não são da área jurídica. André Chervel (1990, p.183) nos faz pensar, especialmente no campo historiográfico, ao pontuar a relevância das disciplinas escolares, questionando inclusive sua "serventia", seus valores e os resultados para os alunos, o autor questiona sobre o repertório que deve ser contemplado para o desenvolvimento profícuo das disciplinas escolares.

A partir do relato de memórias e ao iniciar a docência universitária, ao preparar atividades e ao desenvolvê-las em sala de aula, é possível um educador perceber, por exemplo, que em certos cursos de graduação, a tecnologia é fundamental, vem ao encontro da necessidade de "alfabetizar" o alunado em letramento jurídico quando o perfil profissional do curso não é a área do direito.

\footnotetext{
${ }^{6}$ http://www.aulasdejapones.com.br/alfabeto-japones/

${ }^{7}$ http://www.aulasdejapones.com.br/alfabeto-japones/
} 
Contudo, não basta apenas dizer, mas trabalhar para concretizar o letramento jurídico como uma possibilidade de compreender-se o papel da escrita nos vários âmbitos em que circulam processos, petições e documentos diversos no campo jurídico. Destarte, compreende muitas atividades desenvolvidas na área jurídica, como o desenvolvimento e o aperfeiçoamento da escrita, da interpretação e análise.

Cabe dizer que é fundamental provocar ou instigar a participação ativa dos discentes, a fim de contribuir para a formação de um cidadão consciente de seus direitos numa determinada sociedade; contudo, um item agravante é quando este tipo de prática sequer faz parte dos currículos do ensino nas escolas. Fazendo uma analogia com a questão de um jovem de dezesseis anos possuir o direito ao voto, mas sequer foi instruído devidamente sobre a importância de conhecer o funcionamento do sistema dos poderes executivos e legislativos em nosso país. Um indivíduo não deve votar apenas porque tem direito para votar, mas porque sabe a importância que tem votar numa eleição qualquer no seu país.

Dessa forma, é fundamental refletir o como tornar uma disciplina jurídica interessante quando se aborda certos assuntos jurídicos num curso de graduação, seja num curso da área da Administração ou outra área qualquer.

Nesse sentido, Taborda de Oliveira el al (2014, pp.176) afirmam que:

[..] faculdades de sentir ou experimentar impressões físicas inerentes ao sistema nervoso, pela qual o homem e os animais percebem as sensações causadas pelos objetos exteriores ou nascidas no interior, podem ser consideradas domínio educativo na medida em que se pode ensinar e aprender os usos do corpo. Mas se considerarmos uma das suas outras acepções, aquela que define uma 'faculdade para experimentar impressões morais; disposição para experimentar impressões dessa espécie', então é preciso reconhecer que as sensibilidades são um resultado das respostas que os indivíduos produzem a partir do momento que interagem com o mundo físico ou social.

Os autores advertem que é fundamental trabalhar a sensibilidade do educando e a do educador, a fim de que ambos possam interagir. Compete então ao educador elaborar o conteúdo curricular de uma disciplina ou até mesmo quando está estruturando a base curricular de um determinado curso, buscar respostas a partir das provocações que foram sendo colocadas para uma reflexão crítica.

Assim, ao lecionar uma matéria jurídica, diferentemente da alfabetização em língua japonesa, apenas decorar artigos da lei não contribui para a formação de um administrador consciente e participativo na sociedade, como de nenhuma outra área do conhecimento humano.

O letramento jurídico deve ser pensado também ao indagarmos se a sua finalidade é somente a de busca um resultado útil. Nesse caso, deve-se pensar na questão da sensibilidade, dado que é fundamental esclarecer ao indivíduo que ele não está separado da sociedade. 
Não estamos separados e nem podemos ignorar os termos técnicos da legislação, que nos insere na própria cultura social, a fim de não cairmos na invisibilidade e exclusão ou apenas ser um diplomado, mas desalinhado com a sua cultura e com as relações sociais com os seus pares e os diferentes na comunidade ou sociedade em vive, estuda, trabalha e se realiza como ser humano.

Partindo então em busca da superação provocada por André Chervel (1990) e mobilizada por Taborda de Oliveira et al (2014) nas leituras realizadas para analisar este conto, pode-se compreender que a disciplina jurídica para alcançar sua finalidade em cursos de graduação, quando se estuda a legislação, talvez funcione de maneira mais assertiva quando elaborada e ministrada considerando a relevância de inserir o discente no contexto social contemporâneo, considerando também os grupos ou indivíduos que podem ser afetados pelo desconhecimento da legislação.

E, ainda que não presente nos currículos escolares, o estudo da legislação antes do ingresso no ensino superior, especificamente na graduação em direito, deveria ser um estudo obrigatório e fundamental a fim de evitar mais exclusão do que a que acontece em certos grupos de indivíduos, de maneira assustadora, haja vista, pode-se verificar numa situação particular como foi a das eleições em outubro de 2018, quando os brasileiros, a maioria dos sujeitos votantes escolheu para o congresso nacional, deputados federais, que a maioria ignora quais os impactos que podem ocasionar na sociedade brasileira, dada a sua escolha eleitoral.

Mas se os indivíduos não têm conhecimento e nem formação, não é correto atribuir-lhes responsabilidade pelas escolhas erradas, mas trabalhar para que a educação possa chegar também na esfera da legislação como de interesse da sociedade brasileira de modo geral e não apenas como um caso especifico, num curso superior.

Ao examinar o currículo de uma graduação, por exemplo, do direito, é fundamental considerar que se ele foi criado, pensado no desenvolvimento do profissional que se quer formar, dando-lhe incentivo para dominar o linguajar técnico do letramento jurídico, e em contrapartida, deixando de considerar que quando se trata de ensinar / lecionar a legislação para alunos das mais diversas áreas, uma educação esclarecedora, reflexiva e critica, que opere para despertar a sensibilidade dos discentes não pode faltar, dado que, é necessário trabalhar para conseguir promover a inclusão do grupo de indivíduos.

Essa observação nos parece importante, dado que deve-se buscar o resultado do estudo de uma disciplina jurídica, contextualizando-a, como no momento atual, no qual se tem discutido se de fato aconteceu ou não a extinção do ministério do trabalho, contudo, será que estamos diante de indivíduos desacreditados ou mal-intencionados em suas relações sociais? A questão que nos toca particularmente é como um sujeito pode entrar numa discussão deste porte sem noção alguma de legislação? 
Para Taborda de Oliveira el al (2014, pp.176-177): “[...] Quando os regimes autoritários ou totalitários desenvolvem uma tecnologia do terror baseada na dor e na crueldade, não é porque capturaram justamente aquele ponto onde cultura e natureza se confundem?”.

Um regime autoritário pode estar mais perto do que a gente consegue ver ou admitir. Sendo por isso, fundamental uma vigilância pessoal, do educador e dos educandos, a fim de não disseminar o autoritarismo, cinismo, ignorância ou preconceito, impedindo o desenvolvimento do processo educacional.

É possível dessa citação inferir que, no estudo da história da educação, estamos diante de uma sociedade desconectada com valores fundamentais para assegurar a sobrevivência e a convivência dos indivíduos, que sequer compreendem o quão impactante poderá ser para o trabalhador perder a garantia da fiscalização do meio ambiente de trabalho, e ainda aplaudir o possível fechamento do ministério do trabalho, conforme anunciado no cenário político brasileiro.

\section{ANÁlisE DO CONTO E REFLEXÃO SOBRE O CAMPO DA EDUCAÇÃO DO DIREITO}

A análise do conto nos permitiu repensar as práticas do letramento jurídico no curso de direito. Ao analisarmos que um menino de seis anos se alfabetizou a partir da visualização de frases, conseguindo decorá-las mediante os programas cinematográficos, possibilitando-lhe multiplicar seu vocabulário, caso semelhante ao estudo da língua japonesa por parte do pesquisador deste texto, cabe considerar que, o letramento jurídico ensinado nas diversas áreas do saber, deve ser proposto de maneira a ampliar o campo de saber, permitir interligar grupos e indivíduos com a sociedade, operando para fomentar o campo de sensibilização e criticidade dos cidadãos mais ativos, deixando de serem reféns de arbitrariedades por desconhecimento do sistema do qual estão inseridos.

Tal reflexão também se alinha ao pensamento de Viñao Frago (1943, p. 43) que afirma: “[...] não se deve esquecer que a escola, como qualquer outro tipo de habitação, incluída a própria casa, é uma criação cultural sujeita a mudanças históricas".

Ou seja, a inserção social dos grupos e dos indivíduos justifica a relevância do estudo da disciplina de letramento jurídico em cursos que não são voltados para a formação em direito, como também acompanhar as mudanças dos fatos históricos para esclarecimento dos assuntos abordados numa determinada disciplina.

A tarefa é árdua, desenvolver uma disciplina jurídica, como a de legislação, por exemplo, é também repensar que indivíduos não podem viver em sociedade como se todos fossem autônomos, porque não se busca somente os resultados, mas o processo de conscientização, o que certamente 
influenciará na reconexão da sociedade, e a partir dos fatos históricos reconstruir-se-á um novo presente de inclusão e harmonia numa visão autônoma da sociedade.

Portanto, ao organizar, por exemplo, uma disciplina de legislação trabalhista para um curso superior de tecnologia em logística, deve-se considerar que o alunado não cursa a base do direito, por isso, sua linguagem se comparada com a mesma disciplina ministrada num curso de graduação em direito, o perfil profissional do curso de logística é área que envolve as relações comerciais dentro das operações logísticas nacionais e internacionais, significa que vai muito além de uma simples atividade de um motorista profissional ou de um operador em logística, assim, ao tratar do assunto trabalho, é fundamental considerar o quão será importante contextualizar na disciplina, a importância do trabalho, que na história é tão antigo quanto o homem.

Por via de consequência, pode-se definir o trabalho quando o traduzimos como sendo a maneira que um ser humano busca realizar suas satisfações pessoais. Nesse contexto, para tornar a disciplina palpável ao mencionado curso, chamamos por Le Breton (1953 p.12):

[...] mil florestas na mesma, mil verdades de um mesmo mistério que se esquiva e que jamais se dá senão em fragmentos. Não existe a verdade da floresta, mas uma infinidade de percepções a seu respeito segundo os ângulos de aproximação, de expectativas, de pertenças sociais e culturais.

Parece fundamental o docente se conscientizar que, após buscar o perfil profissional do curso e aplicar a metodologia para ministrar o conteúdo de uma disciplina já pensando no seu repertório, no que tange ao perfil e o como alcançar os resultados, cada turma apresentará um perfil diferente, assim como citado, na concepção de Le Breton, que existem várias expectativas e maneiras diferentes para ensinarmos e nos aproximarmos do aluno, buscando a história e em especial a história do direito do trabalho que ao que parece está sendo esquecida nos bancos escolares, ignorando-se as conquistas trabalhistas pós escravidão, pós revoluções burguesas e pós revolução industrial, já que no passado o trabalho era uma coisa relacionada ao esforço físico, por isso, os nobres não trabalhavam e sim os seus escravos, depois os senhores donos de terras, os chamados senhores feudais, que não trabalhavam, mas os seus vassalos.

De fato, ensinar a legislação trabalhista não pode ser somente passar um conteúdo abrangendo os conflitos trabalhistas e a violação desses direitos em um determinado contrato de trabalho, se não estivermos diante de um profissional, acima de tudo cidadão conectado com a sua sociedade e consciente de seus direitos, o trabalho docente não terá eficácia e nem será compreendido por estes futuros profissionais.

Pontuamos que, diferentemente da alfabetização do conto do menino que aprendeu as palavras pelas frases, como os símbolos e as suas significações na língua japonesa, elaborar um 
currículo vai além disso, será necessário tocar a sensibilidade do aluno, bem como, seu potencial crítico, mobilizando-o para questões e fatores históricos já mencionados anteriormente.

O trabalhador que desconhece o sistema de escravidão que imperou no Brasil e no mundo, o sistema de servidão feudal, acredita que agora, trabalhar autonomamente é mais rentável, contudo, inconsciente ou por ignorância de formação sobre o mercado do trabalho e o mundo dos negócios numa sociedade neoliberal, não percebe que as conquistas históricas ocorridas podem se tornar em vão, quando ele deixa de observar e participar das discussões que giram em torno de sua sobrevivência como trabalhador assalariado, empreendedor ou trabalhador autônomo.

\section{CONSIDERAÇÕES FINAIS}

Ao analisar o conto, ele nos fez refletir sobre a importância do letramento jurídico no ensino superior, seja no curso de direito como em cursos diversificados em que a disciplina de legislação se faz presente no aprendizado na formação superior.

Também, o conto nos fez refletir sobre o individualismo numa sociedade em que os indivíduos são considerados autônomos, no sentido de serem os únicos responsáveis sobre sua condição social, humana e jurídica.

Quando não se questiona o trabalhador ou um futuro formando de um curso, seja do Ensino Médio ou do Ensino Superior, em qualquer área do conhecimento, está em questão a importância do incentivo para que este trabalhador ou formando saiba contextualizar, a fim de que não se sinta desconectado da sociedade.

Portanto, não basta apenas escolarizar ou 'alfabetizar' um indivíduo, o letramento jurídico somente poderá ser trabalhado se houver ensinamento do conceito da lei, ou seja, ao optar por um saber científico unicamente por um conteúdo didático disciplinar, este não surtirá eficácia alguma se não observarmos que se faz necessário trabalhar para educarmos o estudante para que compreenda os fatores históricos e sociais e as interferências provocadas na sociedade, quiçá possamos ajudar pessoas a se transformarem em atores fundamentais para a evolução em sociedade e da sociedade como um todo indivisível.

\section{REFERÊNCIAS}

BILAC, Olavo. Tempos de escola: contos, crônicas e memórias. São Paulo: Boa Companhia, 2015. CHERVEL, A. História das disciplinas escolares: reflexões sobre um campo de pesquisa. Teoria \& Educação, n. 2, p. 177-229, 1990. 
LE BRETON, David. Antropologia dos sentidos. Tradução de Francisco Morás. Petrópolis: Vozes, 2016.

TABORDA DE OLIVEIRA, Marcus Aurélio; OSCAR, Luísa Belotti. Referenciais teóricometodológicos nas pesquisas em história da educação: para uma história das relações entre sensibilidades, tempo livre e formação. Revista Esboços, Florianópolis, v. 21, n. 31, p. 171-193, ago. 2014.

VIÑAO FRAGO, Antônio; ESCOLANO, Agustín. Currículo, espaço e subjetividade: a arquitetura como programa. Tradução Alfredo Veiga-Neto. 2. ed. Rio de Janeiro: DP\&A, 2001, $152 \mathrm{p}$. 